\title{
James Leonard Vaden
}

- Graduated in Dentistry, College of Dentistry, Tennessee.

- Doctor and Master in Orthodontics, University of Tennessee.

- Graduated in History, Vanderbilt University.

- Professor of the Graduation Program in Orthodontics, University of Tennessee.

- Clinical Associated Professor at the University of Michigan in Ann Arbor, from 1991 to 2000.

- Former Chairman and current Director of the American Board of Orthodontists.

- Associate Director of the Tweed Study Course in Tucson Arizona.

- Treasurer of the Tweed Foundation.

- Editor of the Tweed Loop Journal.

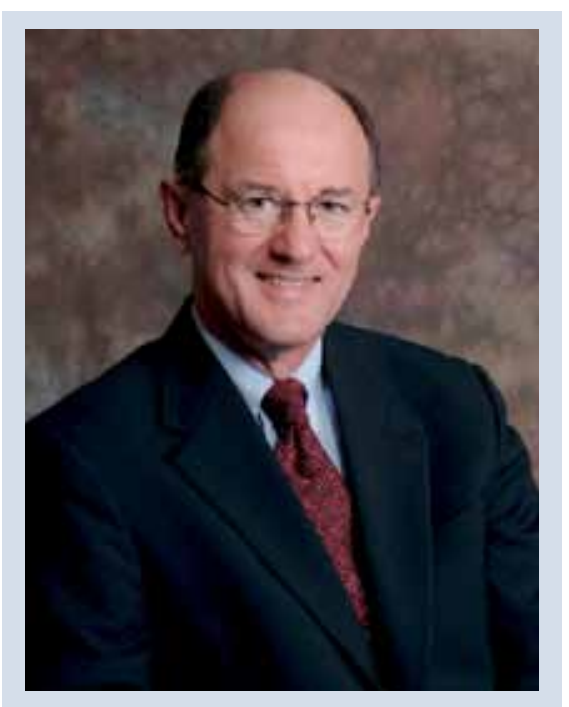

It was with great honor and pleasure that I accepted the invitation to coordinate this interview with Dr. Vaden, for whom I have a deep admiration, especially for his work as a clinician and educator. His clinic life started in 1972 in his office in Cookeville, TN, where, he has been attending children and adults. Over the years, he has been trying to pass his orthodontic experience through more than 120 articles published, as either an author or co-author of 10 chapters of textbooks, in addition to more than 200 lectures carried out in several countries, including Brazil, where he has been five times. He is married to Dr. Beverly Hedgepeth and has a daughter, Meg, a lawyer in New York. He and Beverly live in a farm in the area of Buck Mountain, Vanderbilt, TN, where he raises Angus cattle. In his spare time, he works the land with a John Deere tractor that he had repaired by himself.

Along with well known professors we could prepare questions that express the brilliant opinions of our interviewer on several topics related to contemporary Orthodontics. Have a nice reading!

Estelio Zen 
We have seen in yours presentations the beautiful esthetic results of the patients' faces with treatment plans involving dental extractions. However, many orthodontists seem to ignore the possibility of improved facial aesthetics through extractions. What are the reasons that you point to the strength of these professionals to accept more extractions? Nelson Mucha

I wish I knew the answer to Dr. Mucha's question. I've wondered the same thing many, many

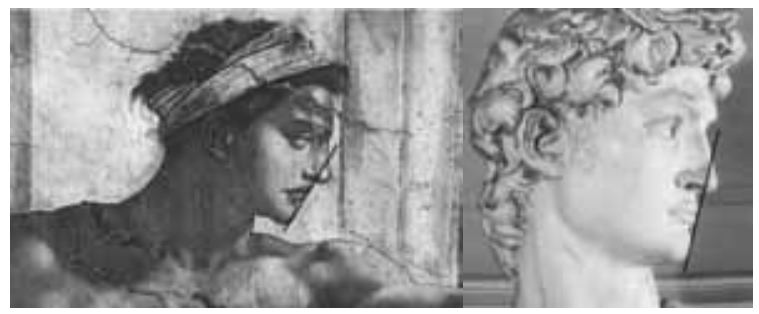

FIGURE 1 - Michelangelo.
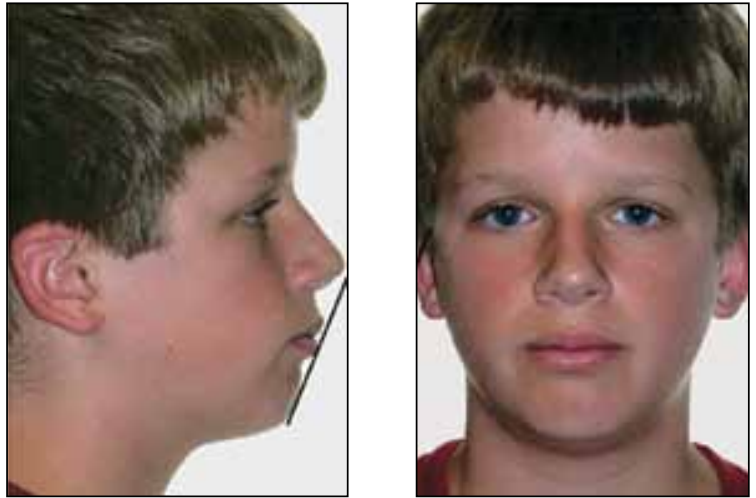

FIGURE 3 - Bialveolar protrusion correction.
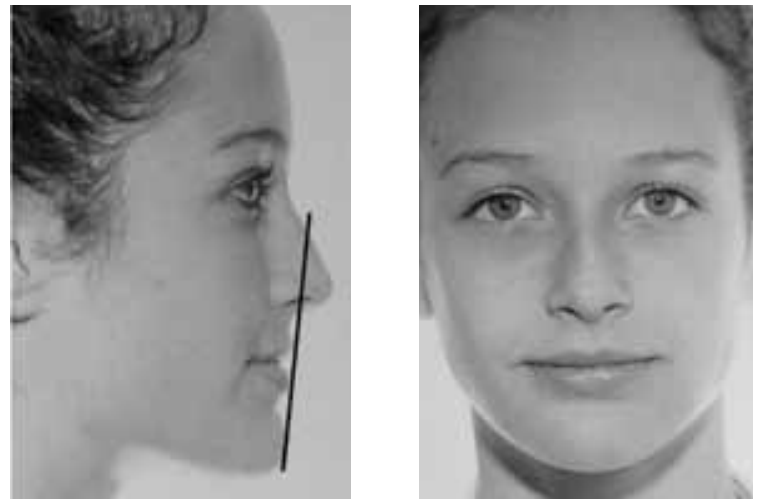

FIGURE 4 - Maintenance of labial balance. times. I don't know why many who practice orthodontics don't have a better understanding of the relationship of facial esthetics and the treatment plan. Each patient should be treatment planned so that the optimum in facial esthetics is achieved. Some say that facial esthetics is an "individual thing" and I constantly hear the phrase "beauty is in the eye of the beholder". If one looks at the subject of facial esthetics from a historical perspective, this is not true. There are standards and guidelines for facial esthetics. Perhaps the

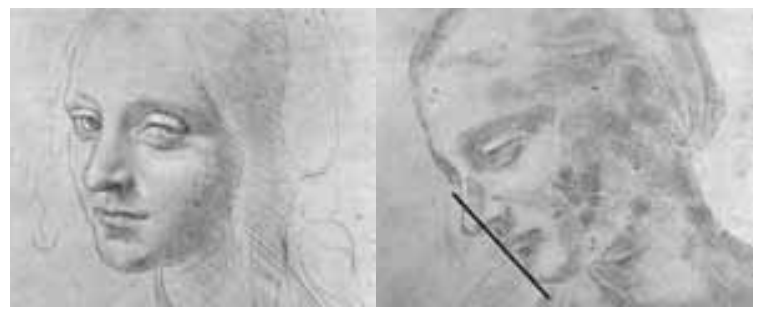

FIGURE 2 - Leonardo Da Vinci.
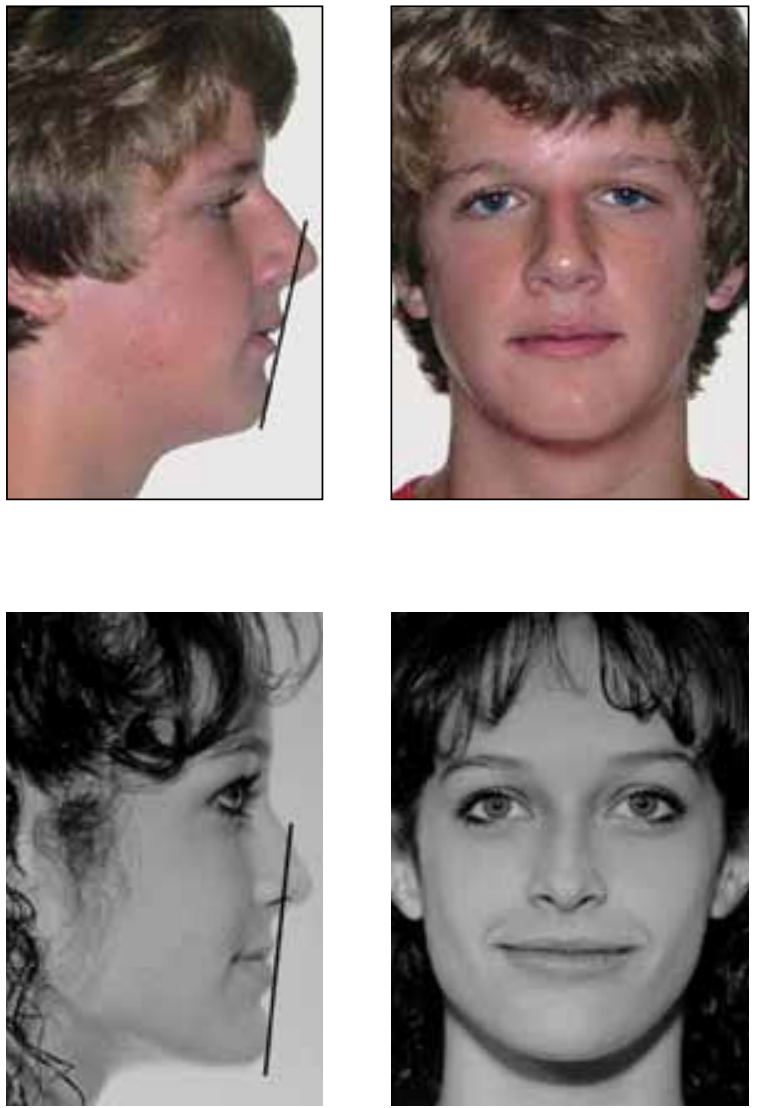
simplest guide that exists was given to us by the Renaissance artists, Michelangelo and DaVinci. These artists used the profile line to determine balance and symmetry of the lower facial profile (Figs 1 and 2). The profile line is a simple tool that is constructed by drawing a line from the soft tissue chin that touches the most prominent lip and that extends upward past the nose. A good relationship of the profile line to the nose is to bisect the anterior $1 / 3$ of the nose. If the profile
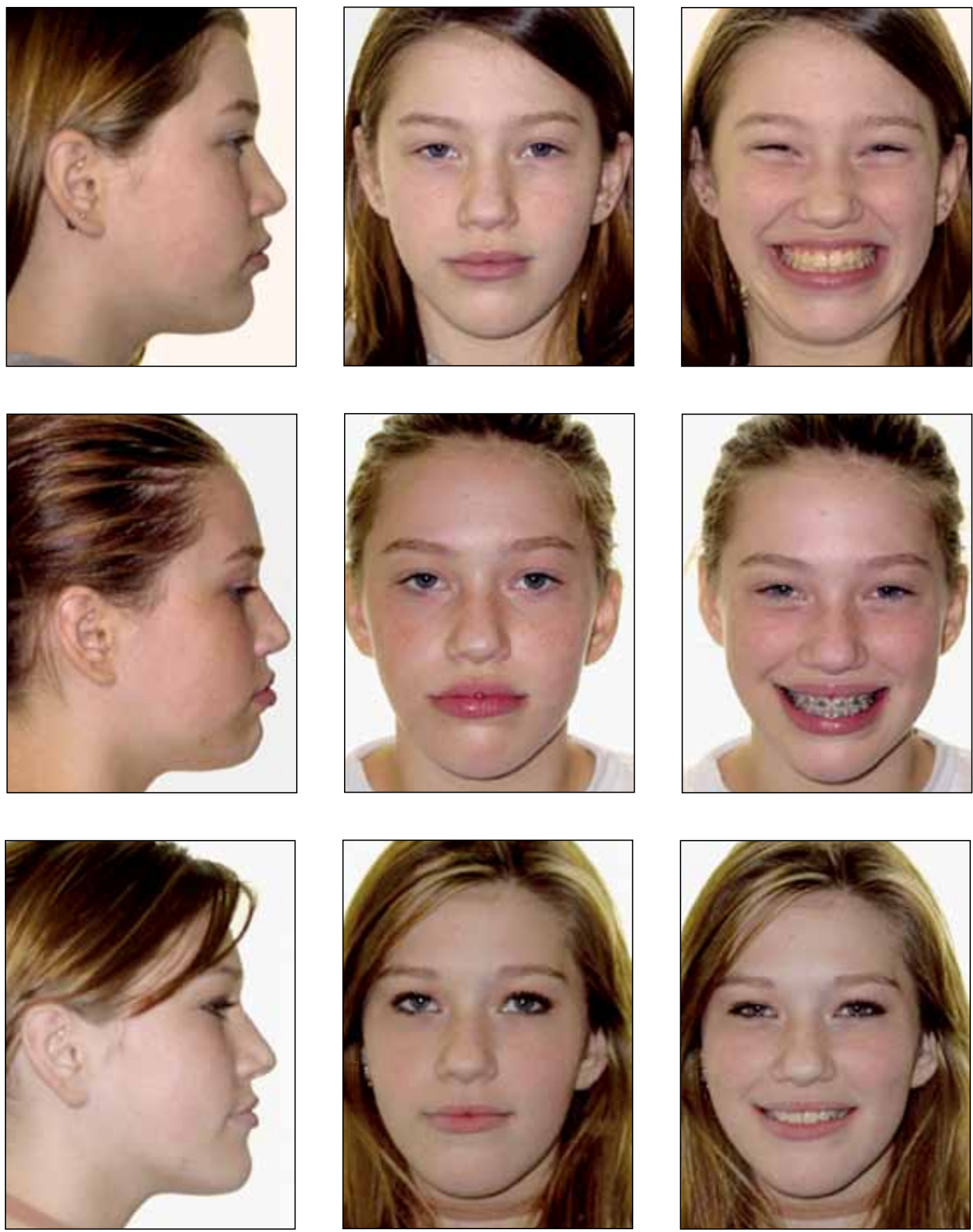

FIGURE 5 - The patient began treatment without extractions and profile worsened. The treatment plan was changed to extractions and back to the original profile. 
line is outside the nose, the patient has a bialveolar protrusion (Fig 3). Reducing the protrusions moves the profile line into the nose. If the profile line is too far "into" the nose, the face is too "concave" (Fig 4). Treatment must not move the profile line further into the nose. I use this simple tool in my treatment plan for every patient. If the patient has a balanced and proportioned face prior to orthodontic treatment, I want to maintain that balance and proportion. If the patient has a bialveolar protrusion-if the lips are too far forward-I want to reduce that protrusion. To reduce a protrusion for most patients requires extractions. Patient $\mathrm{MH}$ had a reasonably balanced face but was started without the removal of teeth even though there was crowding of the teeth. Protruding the teeth to gain alignment created an unsightly protrusion. The treatment plan was altered, extractions were done, treatment was completed and facial esthetics recovered (Fig 5).
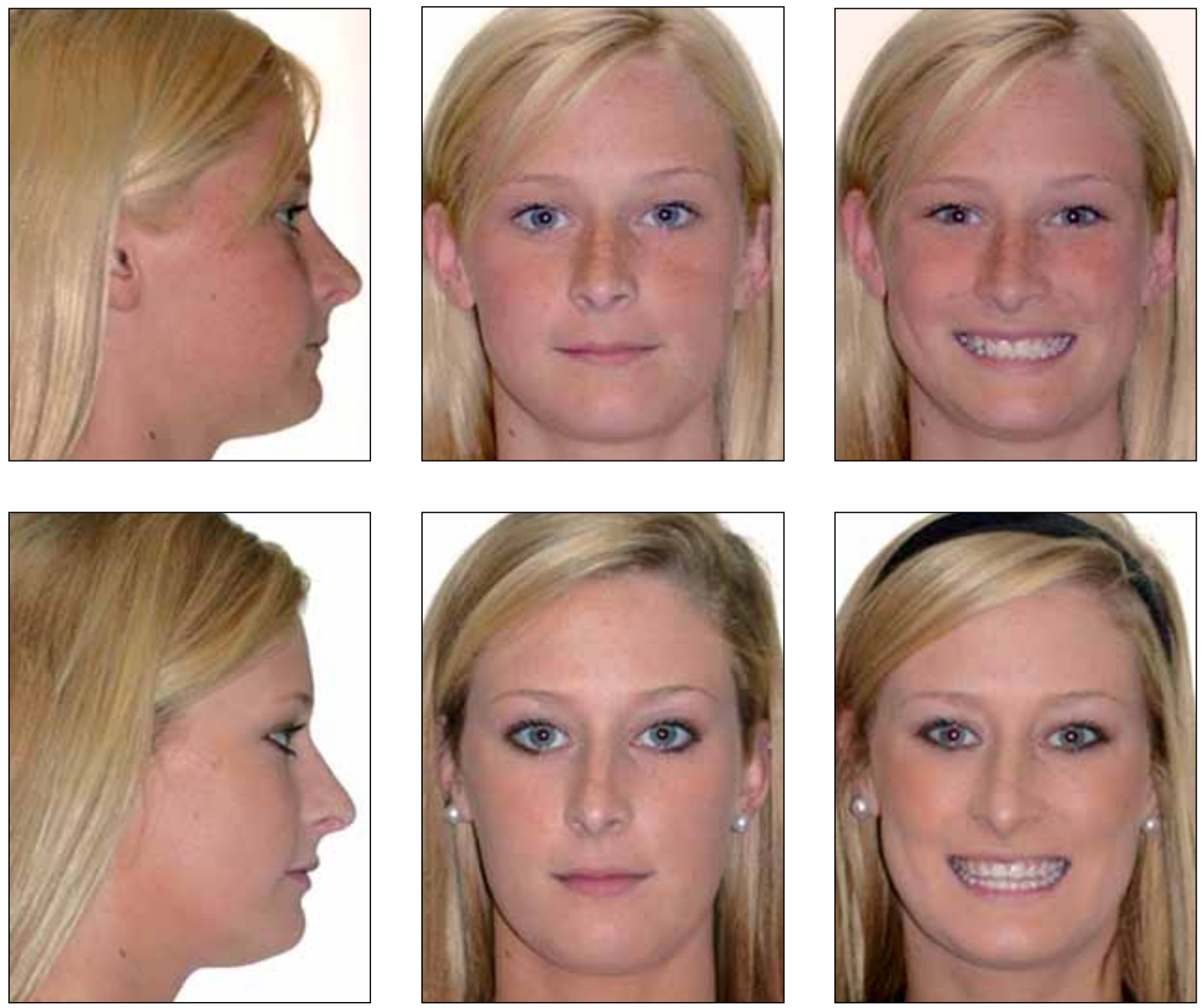

FIGURE 6 - This patient was treated without premolar extraction. Facial balance was preserved. 

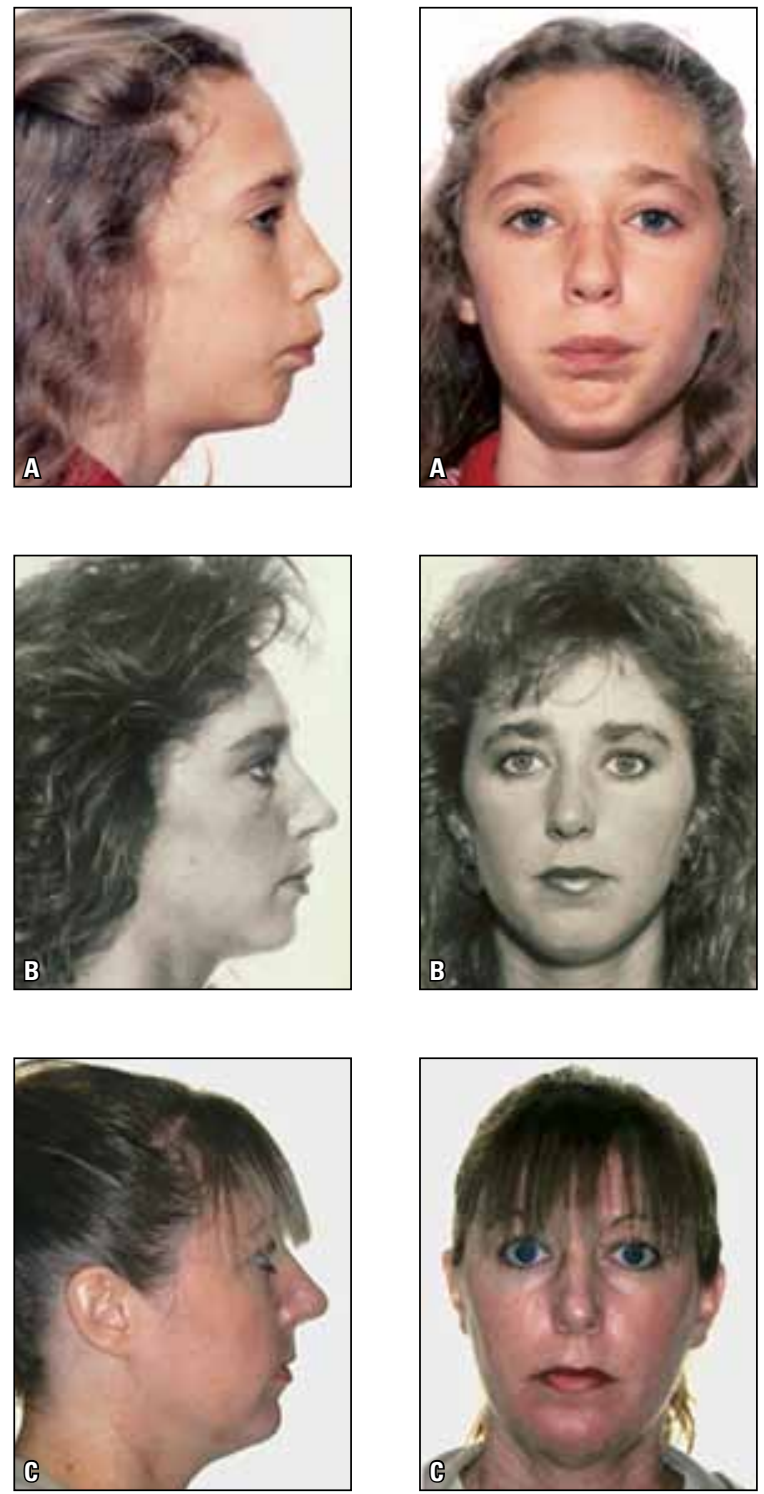

FIGURE 7 - Extractions were used to improve facial balance. Note the proportions of the face at age 42.

Dr. Mucha asks the question of why most orthodontists don't seem to realize the impact of extractions and the fact that extractions can greatly improve facial balance, harmony and proportion for many patients. My feeling is that orthodontics, as a specialty, has gotten so appliance driven that concern for facial esthetics has "gone by the wayside". Some "orthodontists" are, in many instances, placing appliances and using the same series of preformed archwires on every patient to simply align the teeth. The specialty is becoming a specialty of tooth alignment. If we as a specialty don't go back to our roots and our training and become less "appliance driven", we are going to face some serious problems in the future. It's not about extracting teeth or not extracting, it's about doing what's right for the patient's face. If the patient doesn't require extractions for posttreatment facial balance, harmony and beauty, no extractions should be done (Fig 6). If extractions will improve the balance and harmony of the patient's face (Fig 7), the specialty must use this very valuable tool.

With the large supply of "magical treatments, smart archwires, aligners, self ligating brackets", among others, which arguments do you use as a teacher to yours students to maintain high standards for diagnosis, planning and accomplishment of appropriate orthodontic treatments with the need for individualized bends in archwires? Nelson Mucha

Orthodontic education has a great responsibility to teach students the fundamentals that are involved in a careful and methodical system of treatment planning and force system application. Once the treatment plan is reached, the appliances must be placed appropriately and treatment conducted accordingly. It is imperative that students understand that there are no magic appliances and no magic archwires. The patient must be treated by a skillfully trained orthodontist, not by an appliance. Many programs that teach graduate orthodontic students stress fundamentals. These programs have leadership that understands and appreciates the fundamentals. They also have part-time clinical faculty who understand the fundamentals. There are some programs, however, that have faculty who are appliance driven and who have no concept of the fundamentals of orthodontics. The student who trains in this type of program, therefore, has no understanding of treatment planning and of treatment. It is 
not the fault of the student. Our specialty must come to grips with this problem. This is not to say, however, that those programs that stress the fundamentals have graduates who adhere to what they are taught during their training program. Some well trained graduates simply take a couple of the commercial courses that tout the amount of money one can make if they see " $x$ " number of patients in a day with that company's "magic" appliance. These students buy into this commercialism and join the ranks of tooth alignment specialists. This is disheartening to the people who taught them, but we always think they will return to what they were taught when they see that the "quick and easy" doesn't always work. The primary argument we use at my university is "Look at the face. Do what is right for the face and for the long-term stability of your treatment result." We keep repeating this fact. It's heartening that some students listen and practice accordingly. Others who haven't practiced accordingly have realized their error, have reevaluated their practices and have started treating their patients more appropriately. I can assure you that it's a hard problem in today's climate of "everything works and nothing matters". Those of us in orthodontic education have to keep our hope that our students are listening and learning and that, even if they "stray" for a while, will come back to the fundamentals in order to render appropriate treatment for their patients.

In your article published in World Journal of Orthodontics (v. 6, no. 2, p. 115-124, 2005), you stated that the patient who has a diminished anterior facial height and excess posterior facial height must be treated with a different diagnosis and treatment plan. What diagnostic and treatment plan "schemes" must be used? Adilson Tomazinho

The "low angle" patient has short anterior facial height and excessive posterior facial height. As a general rule, this patient has a profile line to nose relationship that is either "correct" or the profile line might even be too far into the nose. One has to carefully treatment plan these patients to preserve facial balance (refer to Fig 6 ) and yet give them a dentition that is esthetic and stable over the long term (Fig 8). In most instances the treatment plan will involve the preservation of mandibular incisor position. The low angle patient does not benefit from uprighting mandibular incisors; in fact, it can be harmful to facial esthetics. Therefore, most of these patients need to be treatment planned so that mandibular incisors are left in their pretreatment positions (Fig 9). This does not mean, however, that one can ameliorate crowding or level the curve of Spee by proclining mandibular incisors. If the patient has significant crowding, teeth must be extracted, but it's normally the mandibular second premolars. Crowding is eliminated for these patients and the space that remains must be closed by mesial movement of the mandibular posterior teeth so that mandibular incisor position is protected. The records of the following patient illustrate this concept (Fig 10). In some instances, if there is not significant mandibular crowding, the curve of Spee can be leveled with an approach that utilizes a headgear to the mandibular arch along with early removal of mandibular third molars. This allows one to level the mandibular arch without flaring mandibular incisors. Quite honestly, the treatment of these patients revolves around how one can manage the mandibular arch-if there is a deep curve of Spee and/or if there is crowding. The mandibular incisor cannot be flared to correct these two problems. The case report that follows illustrates this concept. The patient was treated by leveling the curve of Spee and eliminates the crowding with third molar extraction and the use of a mandibular J-hook headgear (Fig 11).

Conventional orthodontic treatment of the patient who has excessive anterior facial height with open bite is difficult. Many times, it is necessary to make surgical-orthodontic treatment. What nonsurgical orthodontic treatment options can give to the patient 

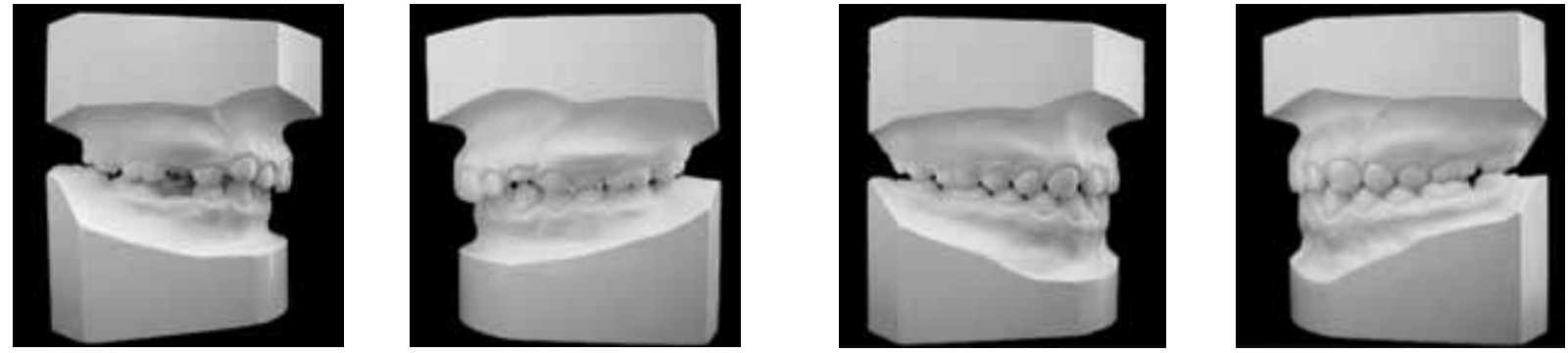

FIGURE 8 - An esthetic, stable dentition.

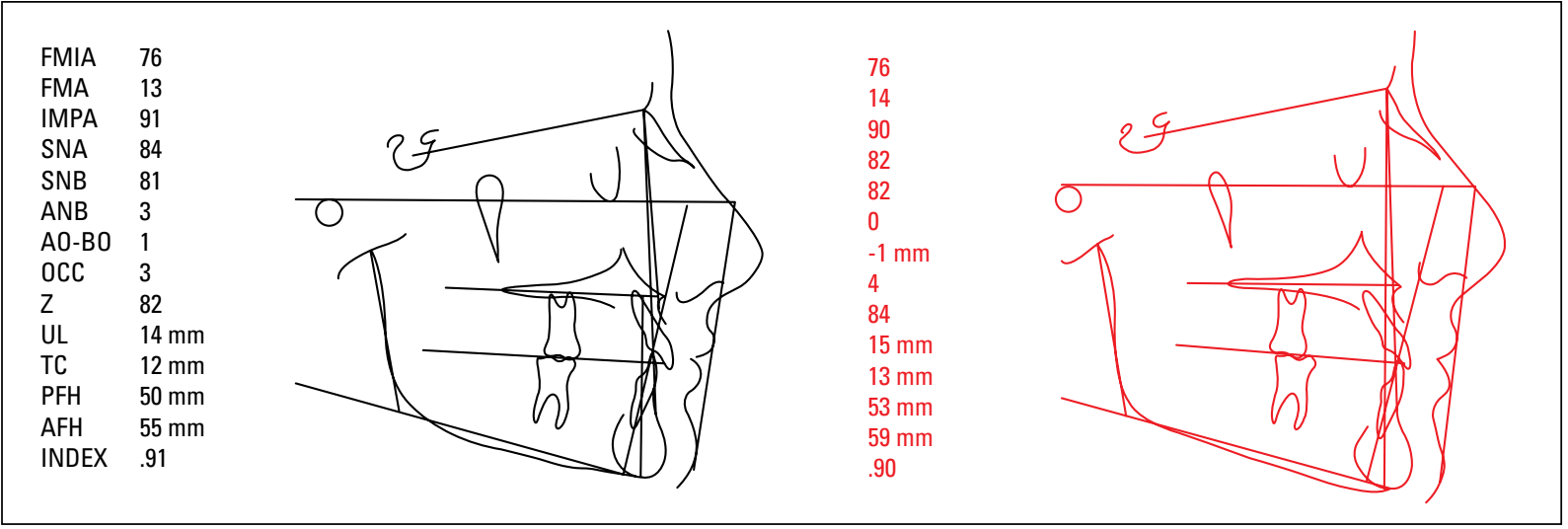

FIGURE 9 - Pretreatment and posttreatment tracings: Note maintenance of the mandibular incisor positions.
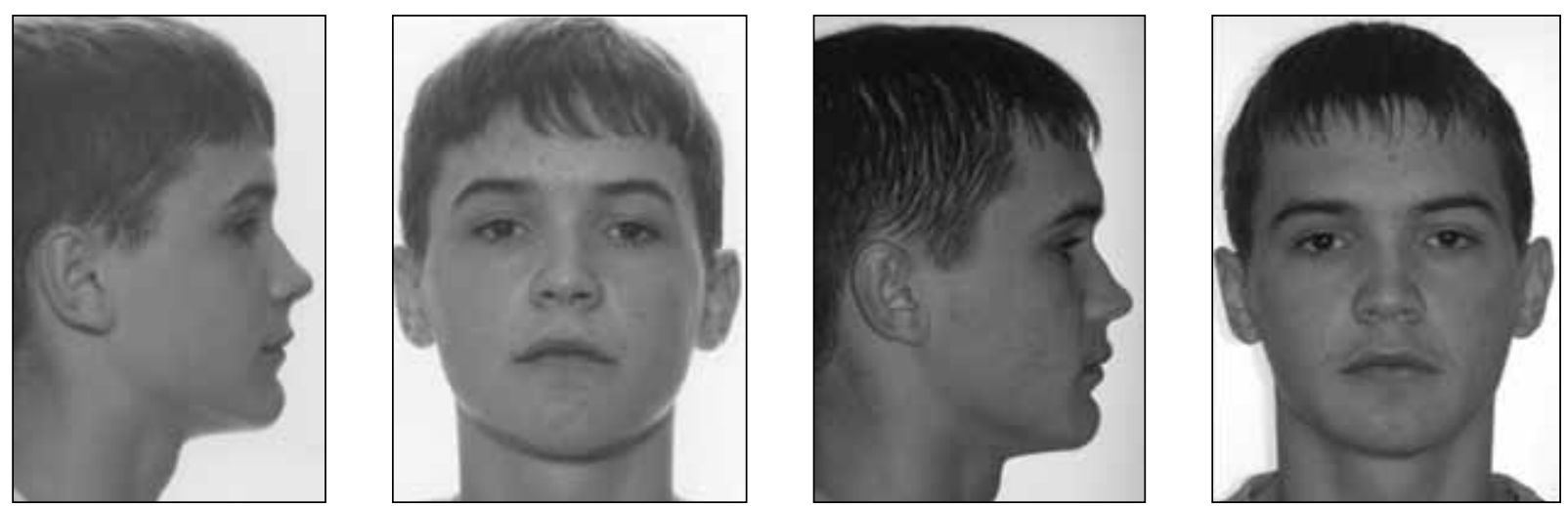

FIGURE 10A - Pretreatment and posttreatment facial photographs: Note maintenance of facial balance.

acceptable facial balance and a good functional occlusion? Adilson Tomazinho

The Class II high angle patient, particularly one who also presents with an anterior open bite, is difficult to treat without surgical intervention. There are treatment planning approaches, however, that the orthodontist can use to treat these patients.
I preface my answer by saying that in most instances the patient might receive a better facial esthetic result if surgical orthodontics is done. However, this doesn't mean that the teeth will not fit together properly and that the patient won't have a functional occlusion that lasts and that is stablealong with reasonable balance and harmony of the 

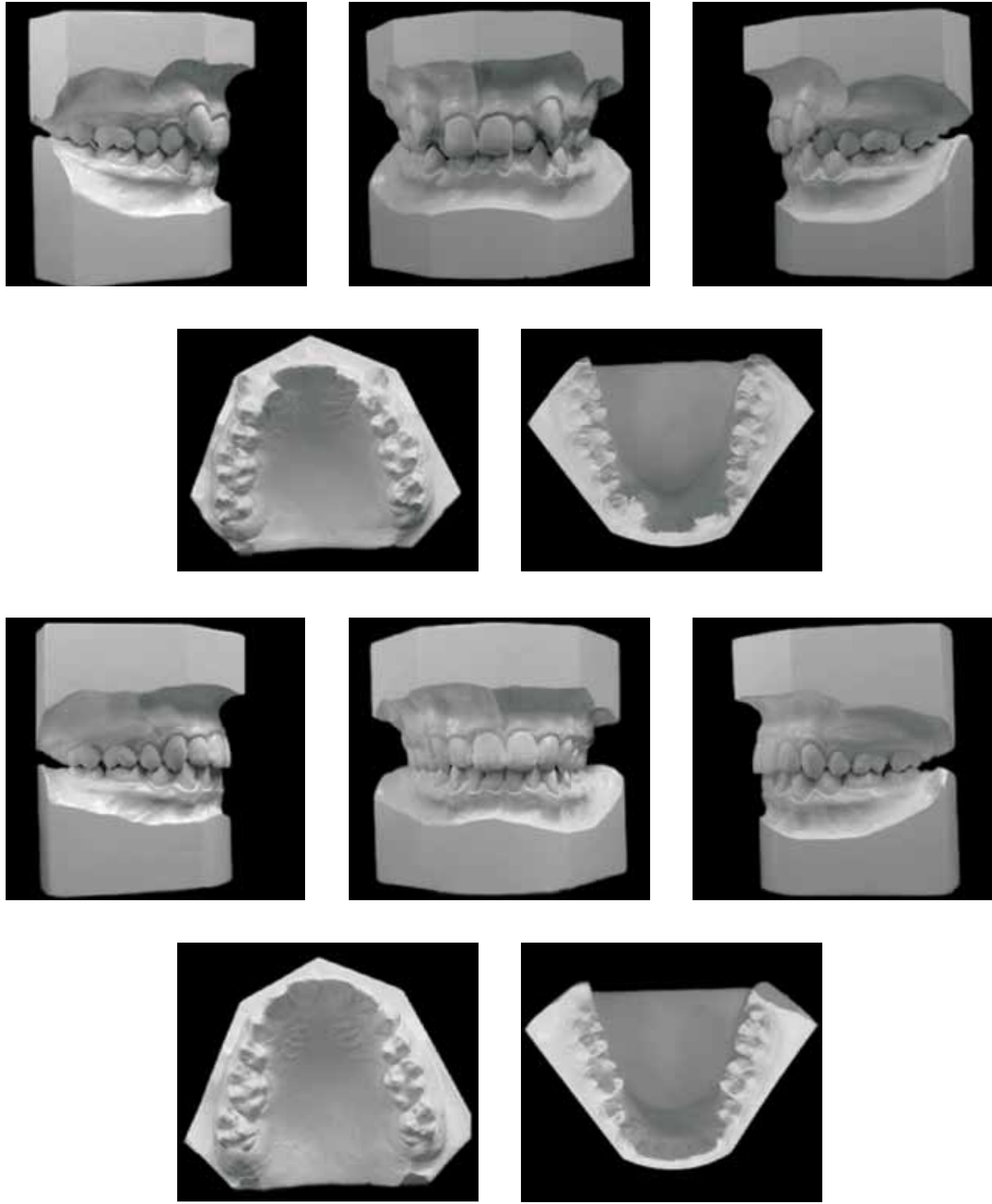

FIGURE 10B - Pretreatment and posttreatment casts: the dental relationship has been corrected. Arch form has been preserved. 

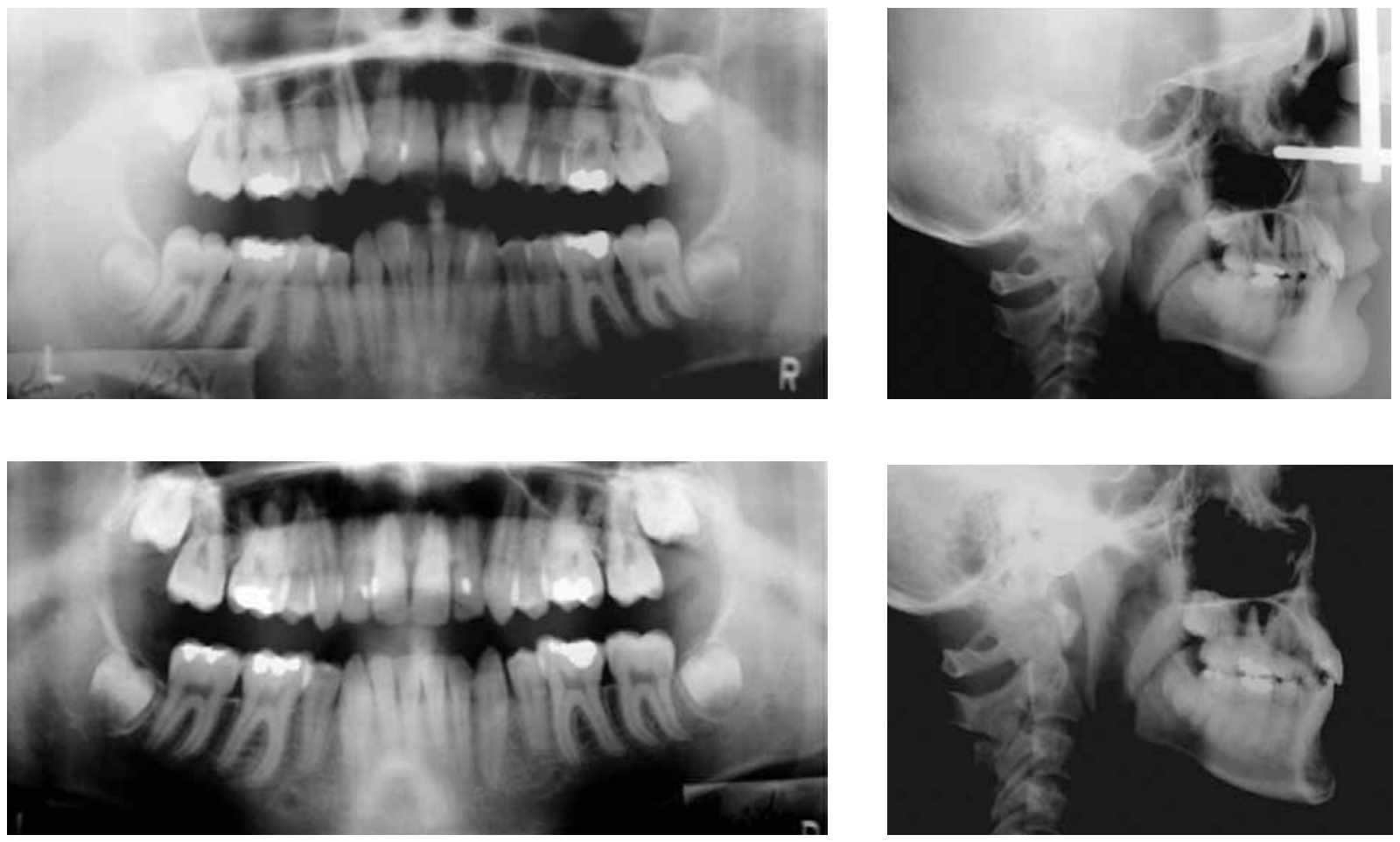

FIGURE 10C - Pretreatment and posttreatment panoramic and cephalometric radiographs.

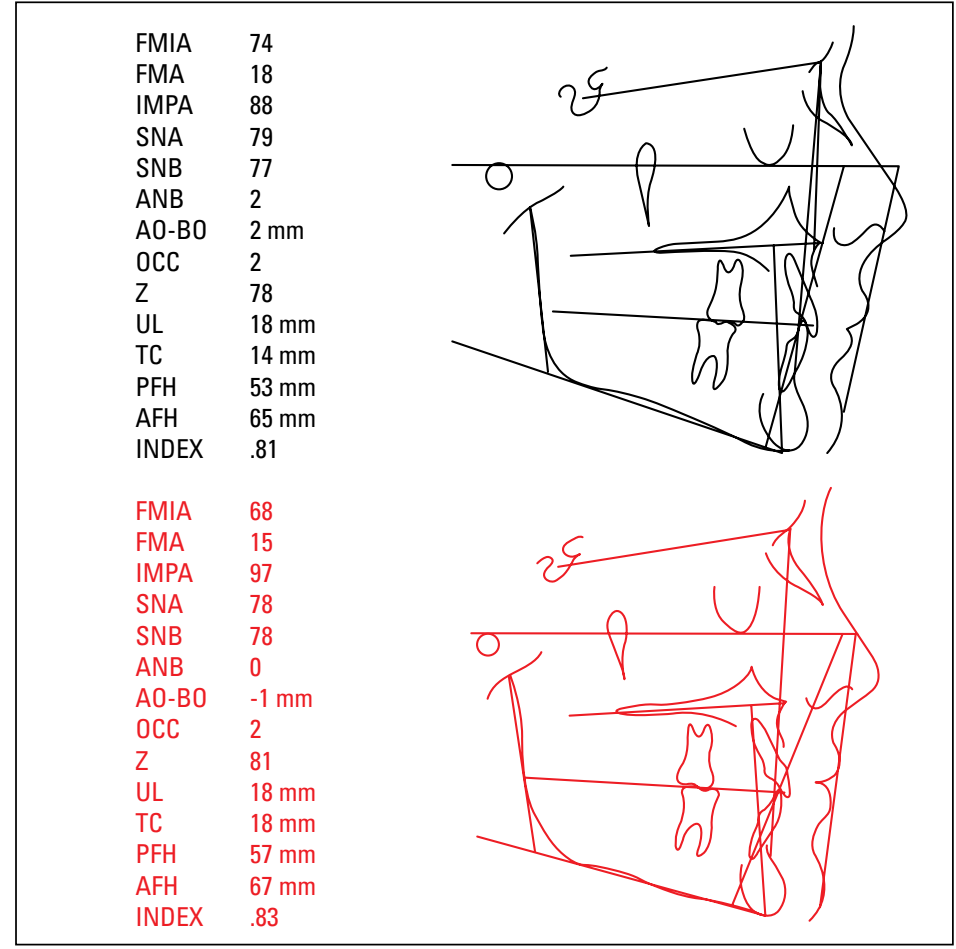

FIGURE 10D - Pretreatment and posttreatment cephalometric tracings.

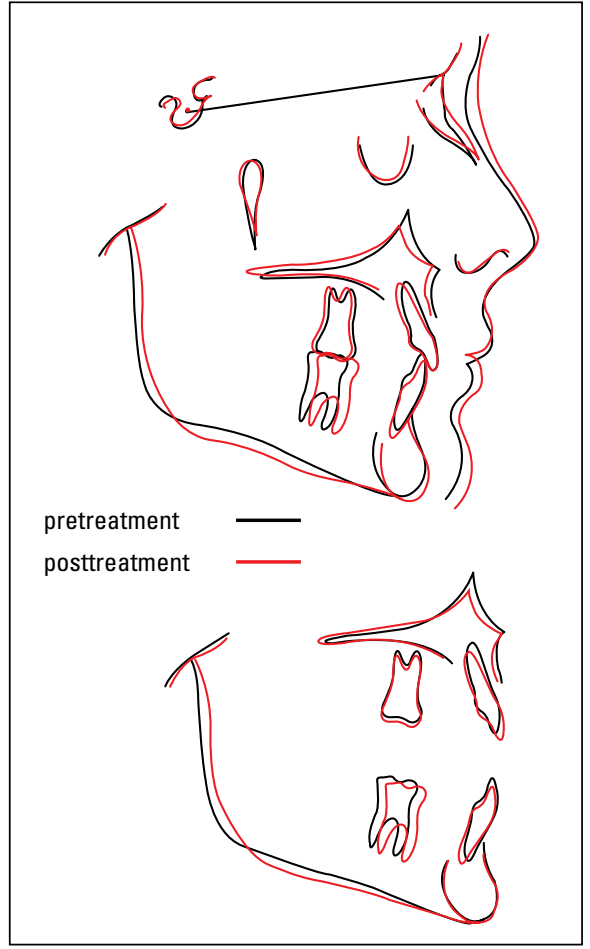

FIGURE 10E - Superimpositions. 

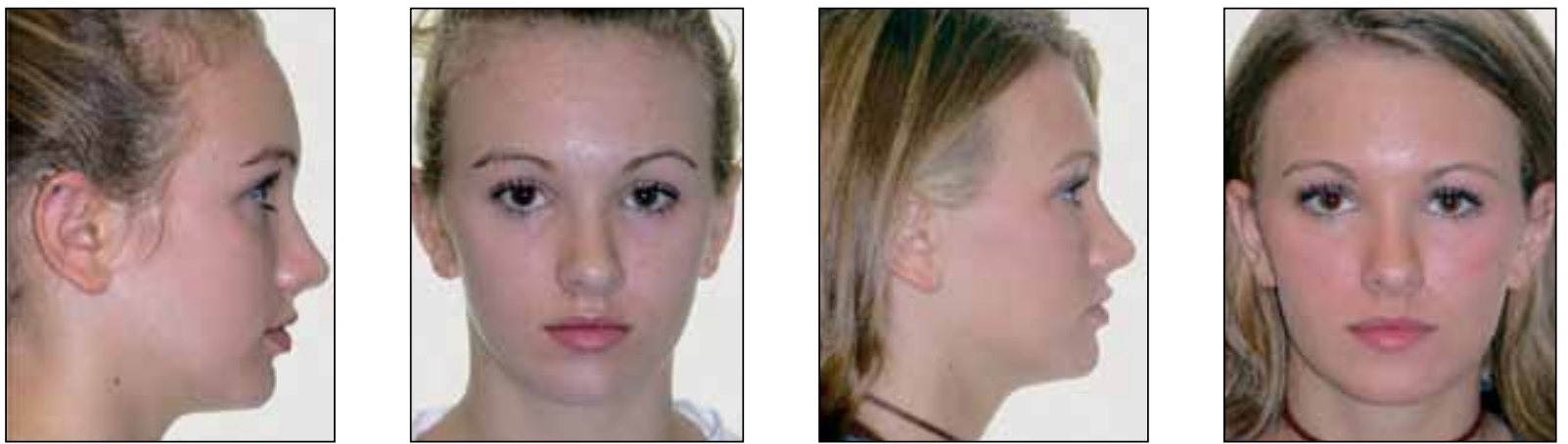

FIGURE 11A - Pretreatment and posttreatment facial photographs.

lower face. There are several guidelines that must be followed if these patients are to be successfully treated with orthodontics only:

- Guideline \#1: The mandibular incisors must be more than upright over basal bone. The higher the mandibular plane angle, the more the incisors must be upright (Fig 12).

- Guideline \#2: Vertical dimension must be controlled. The clinician has to carefully control the extrusion of the mandibular and maxillary molars. If patients are growing, there is going to be normal growth and development of these teeth. However, no excessive extrusion in the posterior areas can occur. If it does occur, the patient's facial esthetics will be severely compromised (Fig 13).

- Guideline \#3: There must be no expansion of the dentition. When the treatment plan is devised, the nonsurgically treated high angle patient might need more teeth removed than one would ordinarily surmise. In other words, one has to have space to a) eliminate crowding, b) upright the mandibular incisors over basal bone, c) level the curve of Spee, and d) correct the Class II dental relationship. In order to accomplish all of these goals, a lot of space is required, particularly for the high angle patient.

These guidelines are critical. The following case report illustrates many of these concepts.
As one examines the malocclusion, it should be apparent that the crowding and protrusion must be corrected by the removal of the maxillary and mandibular first premolars. Because of the high mandibular plain angle, mandibular incisors must be upright and the maxillary anterior teeth must be retracted and intruded. If these things are accomplished, there will not be space to correct the posterior occlusion. In order to achieve a satisfactory Class I occlusion, more space is required. The treatment plan, therefore, required that the patient be reevaluated after all premolar extraction space is closed. At this juncture, the maxillary first molars and mandibular third molars were removed. The removal of the mandibular third molars facilitated anchorage preparation and vertical control of the mandibular arch. The removal of the maxillary first molars provided space for further retraction of the maxillary anterior dentition and mesial movement of the maxillary second molars into a Class I interdigitation with the mandibular first molars. Maxillary third molars were used as substitutes for the maxillary second molars (Fig 14).

This type of treatment takes an additional eight to ten months in most instances, and it must be reiterated that facial esthetics is compromised somewhat from what could be achieved with a 

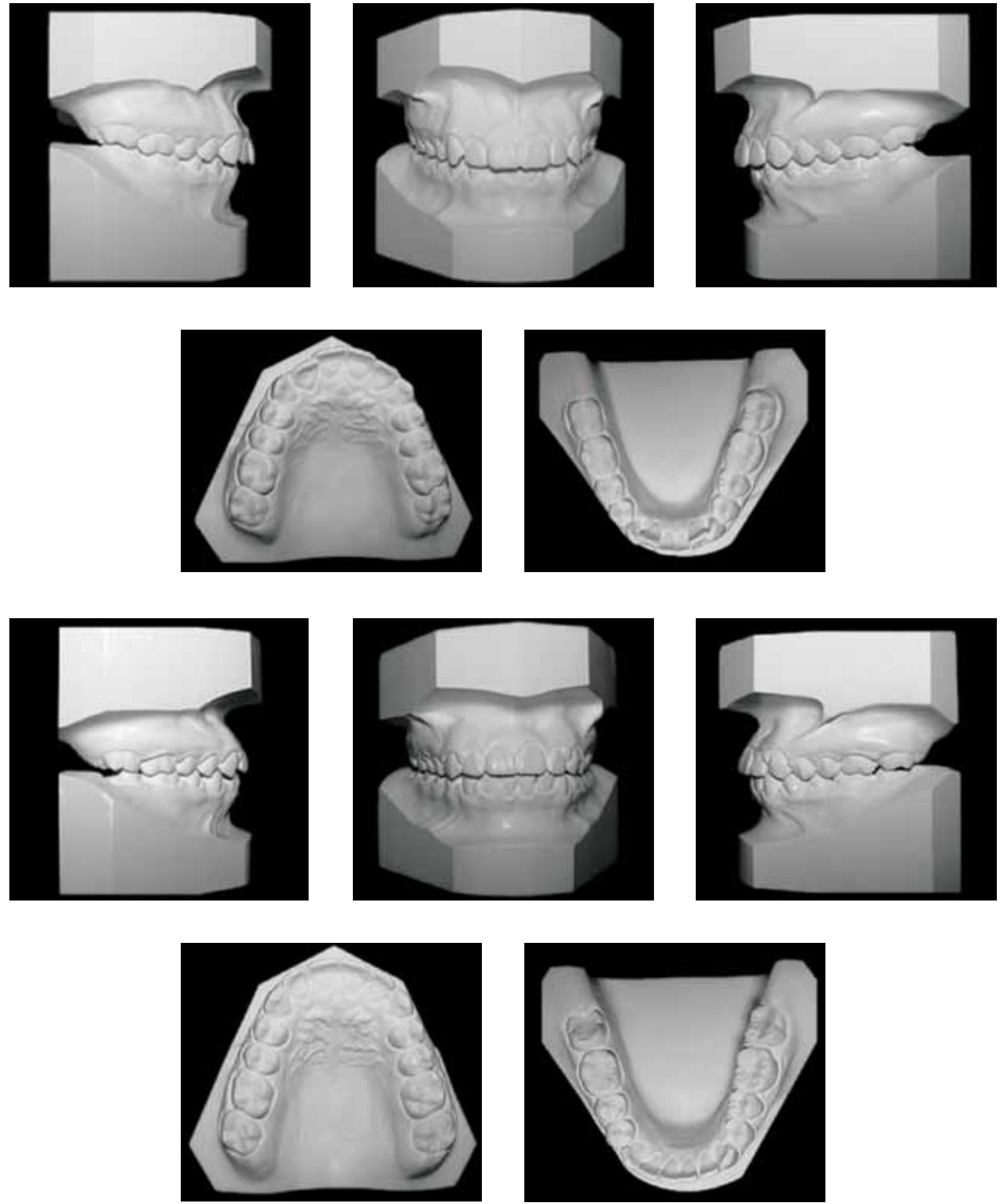

FIGURE 11B - Pretreatment and posttreatment casts. 

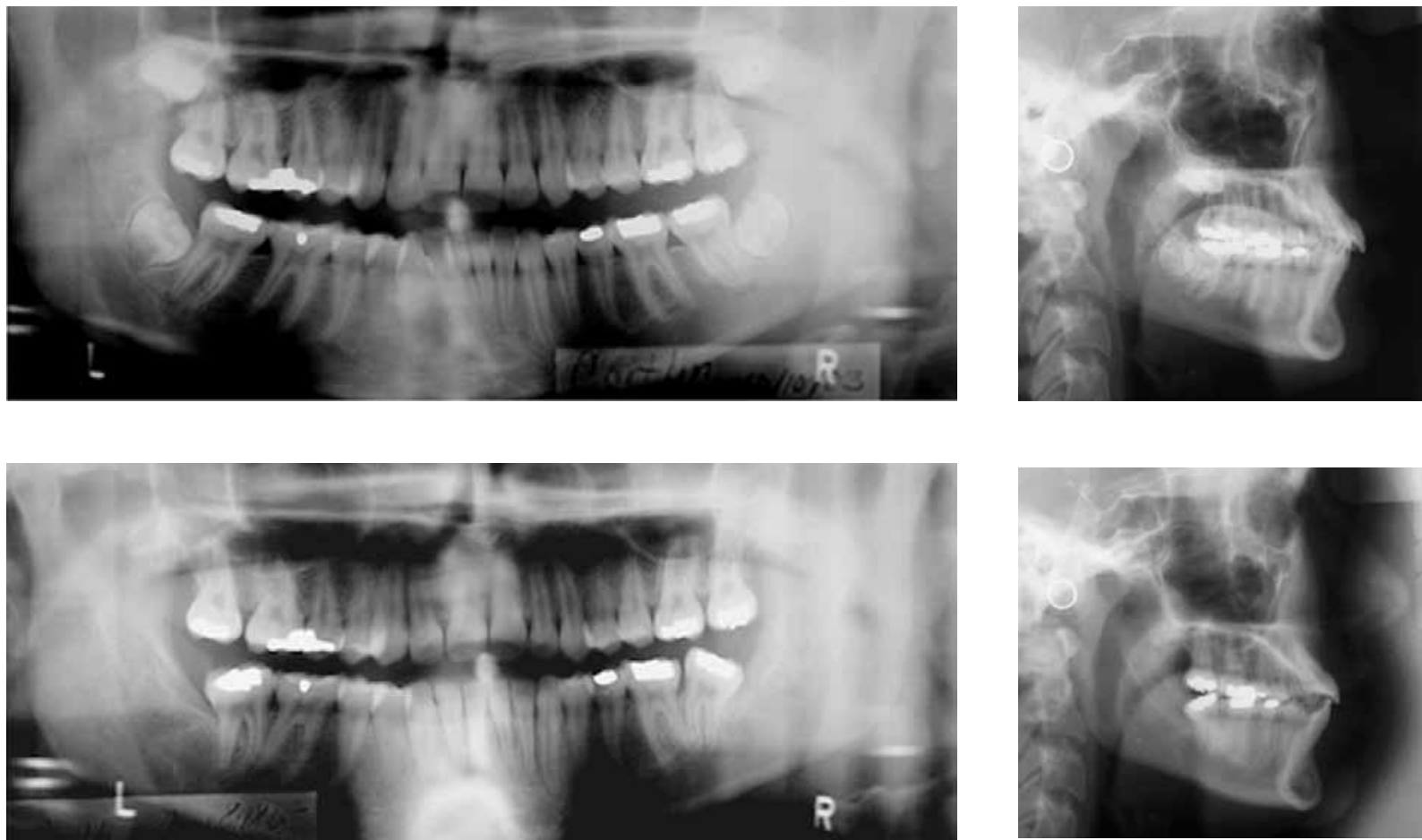

FIGURE 11C - Pretreatment and posttreatment panoramic and cephalometric radiographs. Observe the control of the mandibular arch.

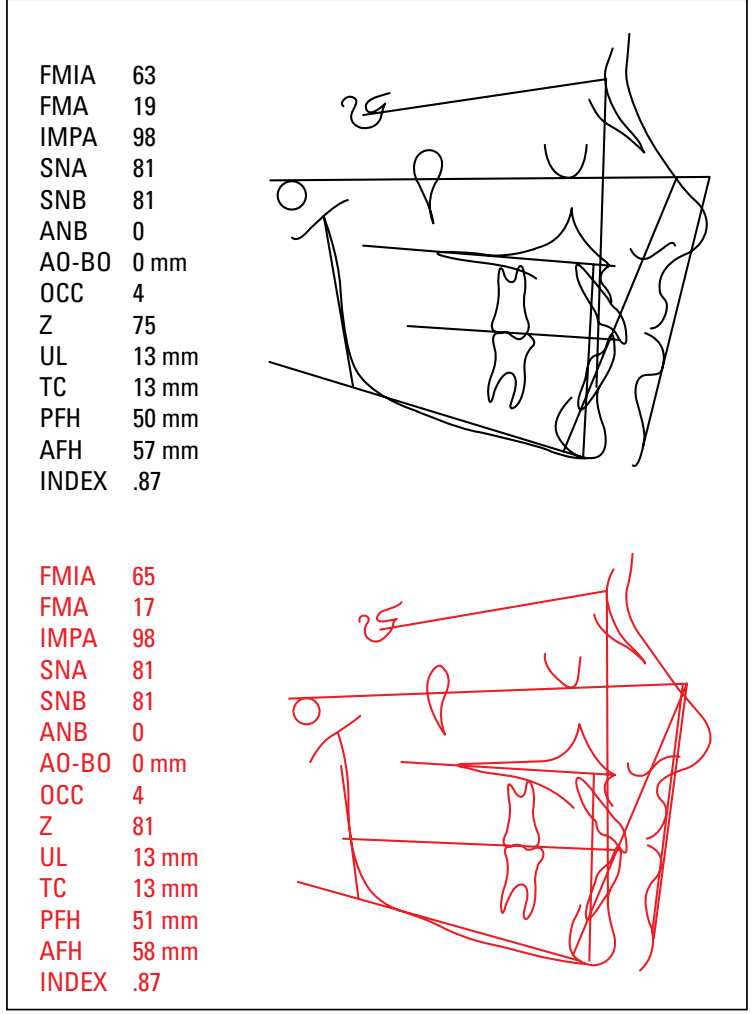

FIGURE 11D - Pretreatment and posttreatment cephalometric tracings.

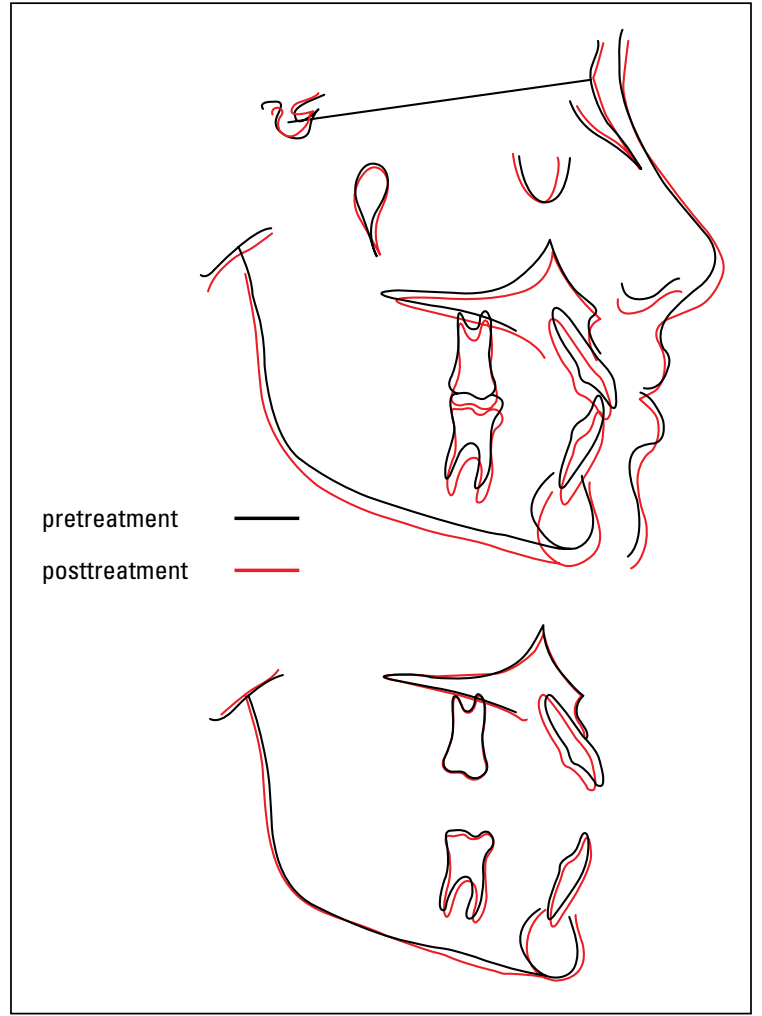

FIGURE 11E - Superimpositions. 

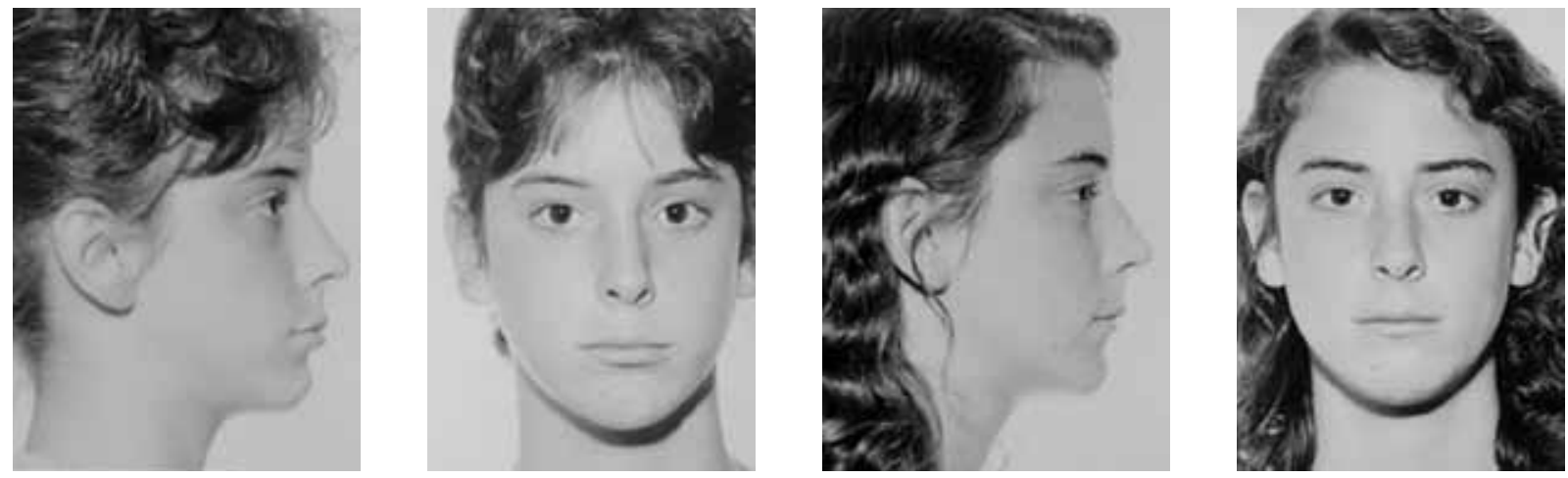

$\begin{array}{ll}\text { FMIA } & 55 \\ \text { FMA } & 35 \\ \text { IMPA } & 90 \\ \text { SNA } & 77 \\ \text { SNB } & 74 \\ \text { ANB } & 3 \\ \text { OCC } & 15 \\ \text { Z } & 75 \\ \text { UL } & 13 \mathrm{~mm} \\ \text { TC } & 13 \mathrm{~mm} \\ \text { PFH } & 38 \mathrm{~mm} \\ \text { AFH } & 63 \mathrm{~mm} \\ \text { INDEX } & .60\end{array}$
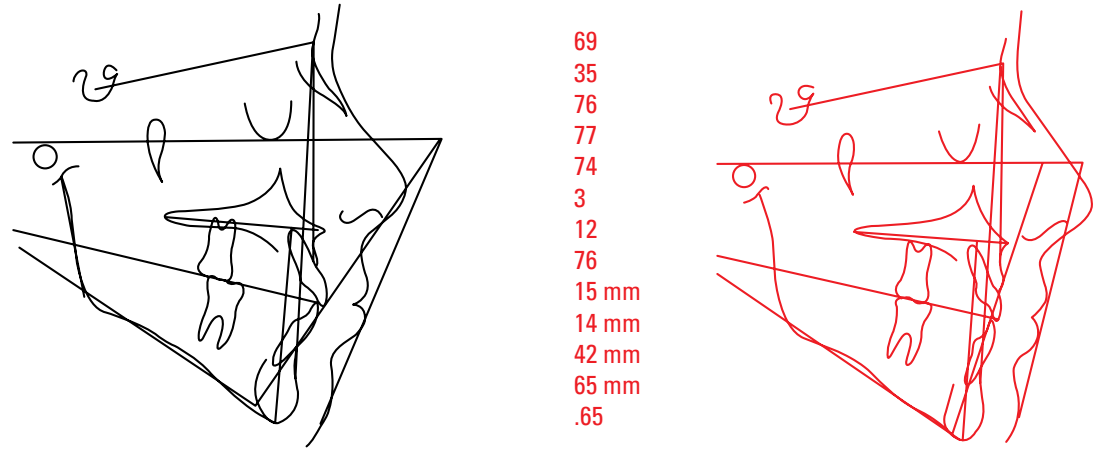

FIGURE 12 - Pretreatment and posttreatment facial photographs and cephalometric tracings. The FMA dictated that mandibular incisors be uprighted to preserve facial balance.
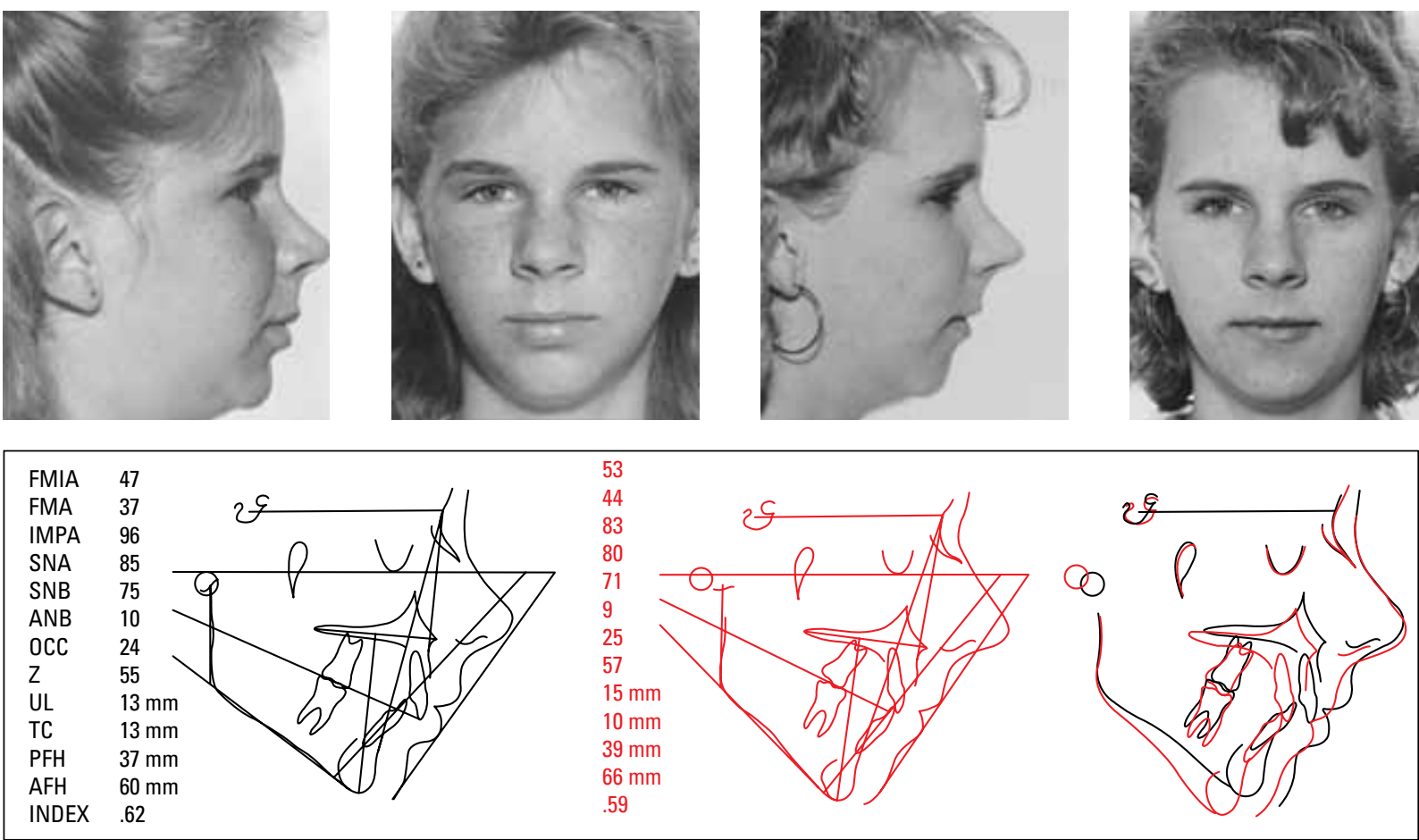

FIGURE 13 - Pretreatment and posttreatment facial photographs, superimpositions and cephalometric tracings. The FMA was opened due to molar extrusion. The facial contours and balance suffered. 

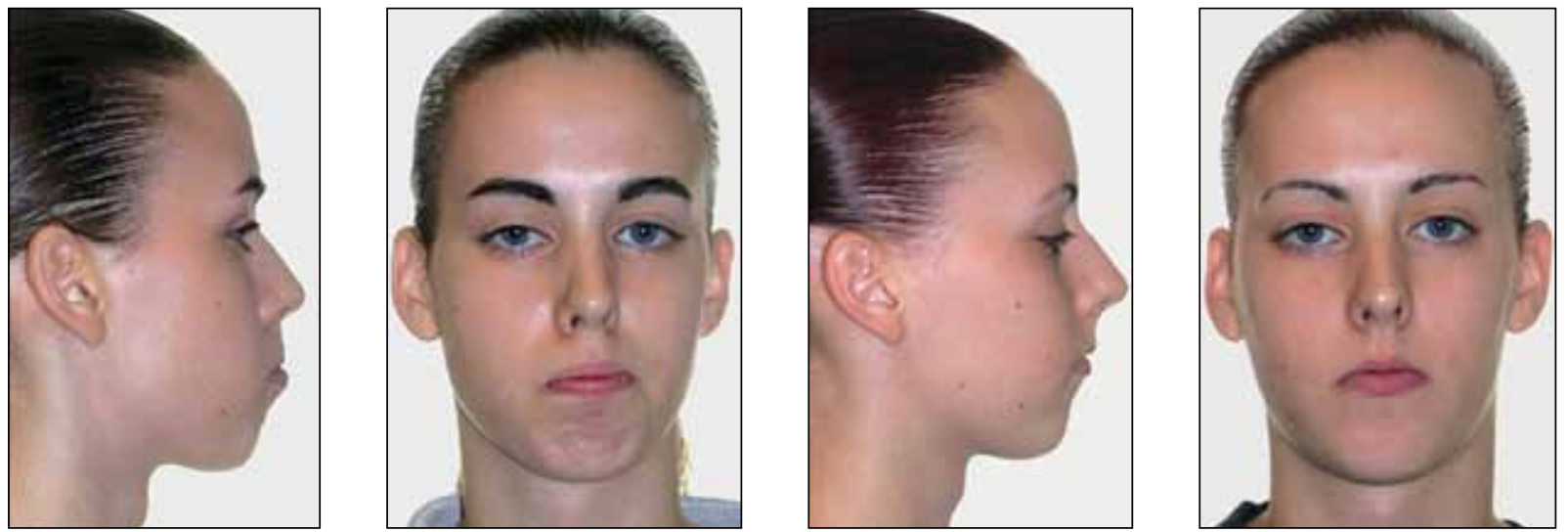

FIGURE $14 \mathrm{~A}$ - Pretreatment and posttreatment facial photographs. Facial balance, though "perfect", is significantly improved.

surgical orthodontic approach. The patient will, however, if treatment planned properly, have an acceptable esthetic result as well as a functional, stable and healthy dentition. This type of treatment plan, though a bit unusual, is required for the severe high angle, Class II malocclusion who declines the surgical option. If this type of patient has a malocclusion that is compromised by an anterior open bite, the same principles apply, but one might use temporary anchorage devices or mini-screws to intrude the maxillary posterior segments. Additionally, tongue posture problems must be eliminated. The bottom line is that the clinician must use every tool at his/her disposal in order to carefully and methodically correct a "surgical" malocclusion without surgery.

What your opinion about the use of mini-implant and miniplate as anchorage in Orthodontics? Adilson Tomazinho

Many case reports have been presented in the literature that show the successful use of miniscrews and miniplates as anchorage units. I think the specialty has accepted the fact that these devices are quite good adjuncts to treatment mechanics for selected patients. One problem, however, is that I have seen miniscrews used to attempt to change an extraction treatment plan into a nonextraction plan by enmass distalization of the entire maxillary arch. I think that the use of these types of devices in an attempt to drastically alter treatment plans is a mistake. In other words, YES, use them when they can improve the treatment result or make treatment possible, but don't use them indiscriminately to do things that shouldn't be done.

Up until 15 or 20 years ago, the Tweed-Merrifield Technique and its followers were criticized for: utilizing heavy forces, extracting too many teeth and flattening the profile. Nowadays, there is much more approval, even in the American Association of Orthodontists (AAO). We know that you and Dr. Jack Dale played an important role in this transition. Did the Tweed-Merrifield Philosophy change or did the general thought change? Hiroshi Maruo

Those of us who use the standard edgewise appliance, and have used it for years, are in a small minority of practicing orthodontists. We will always be a minority in orthodontics because of: 1) the nature of the people who practice the specialty, and 2) the influence that the supply 

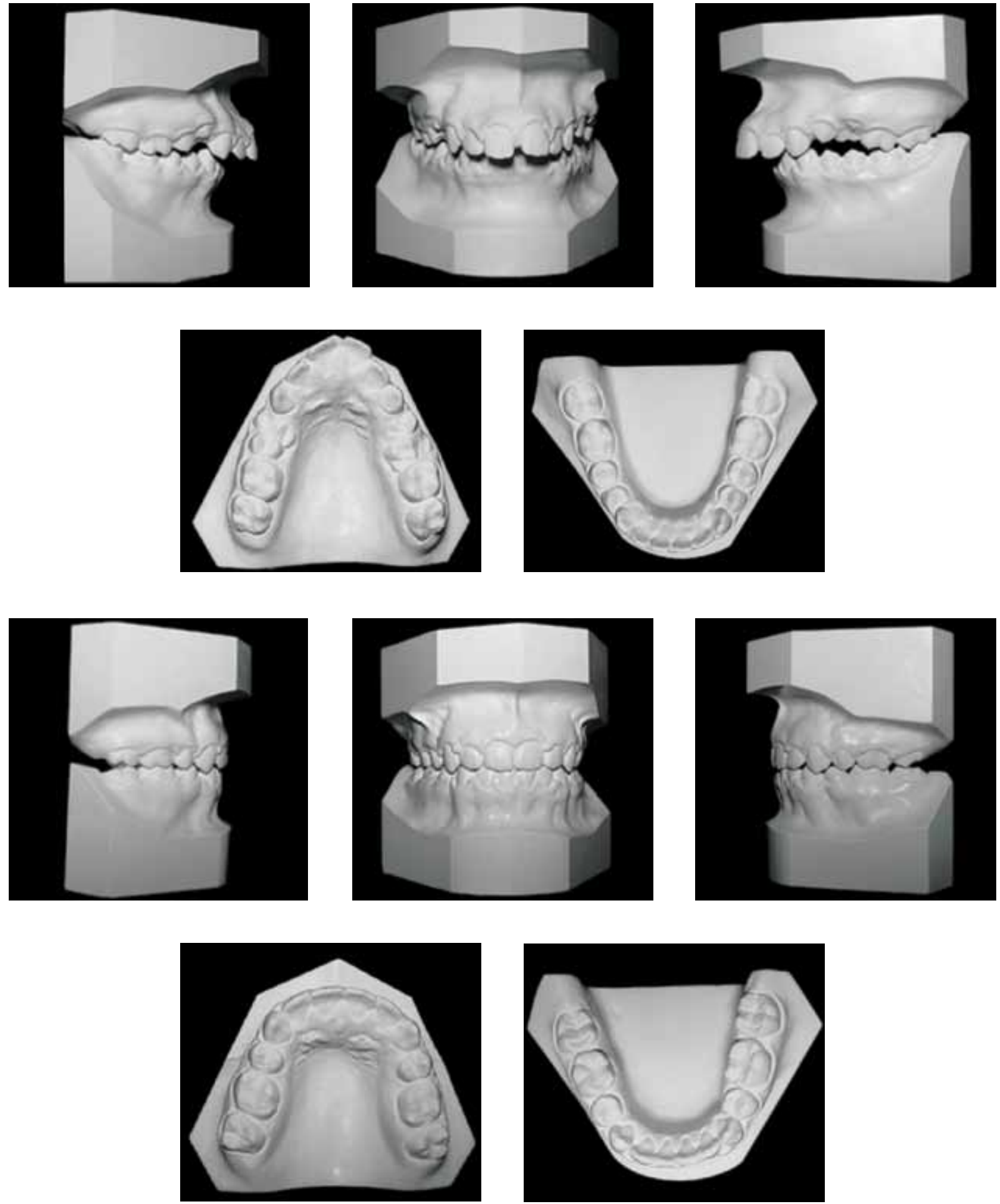

FIGURE 14B - Pretreatment and posttreatment casts: The second molars have been substituted for first; third molars for second molars. 

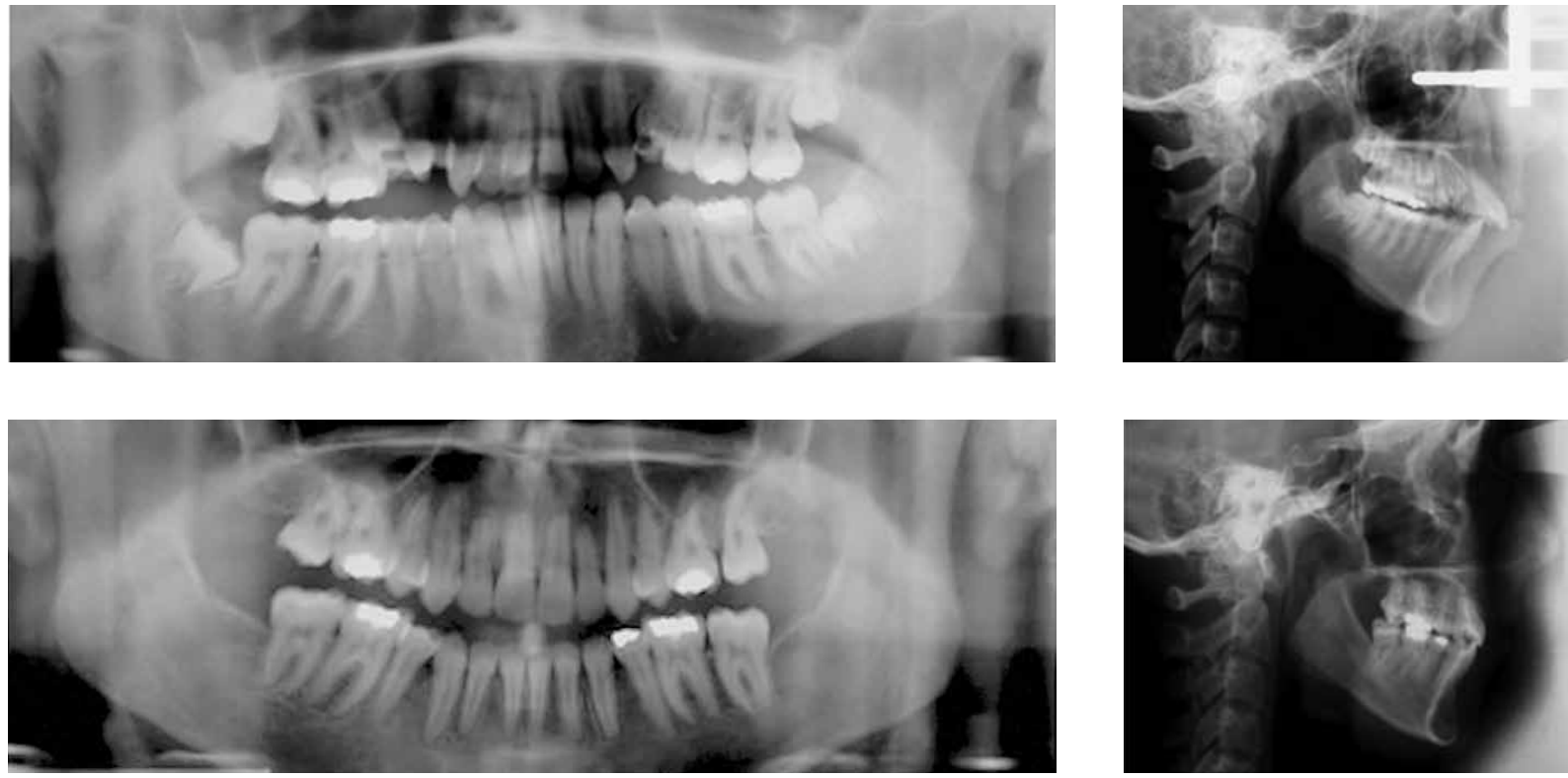

FIGURE $14 \mathrm{C}$ - Pretreatment and posttreatment panoramic and cephalometric radiographs.

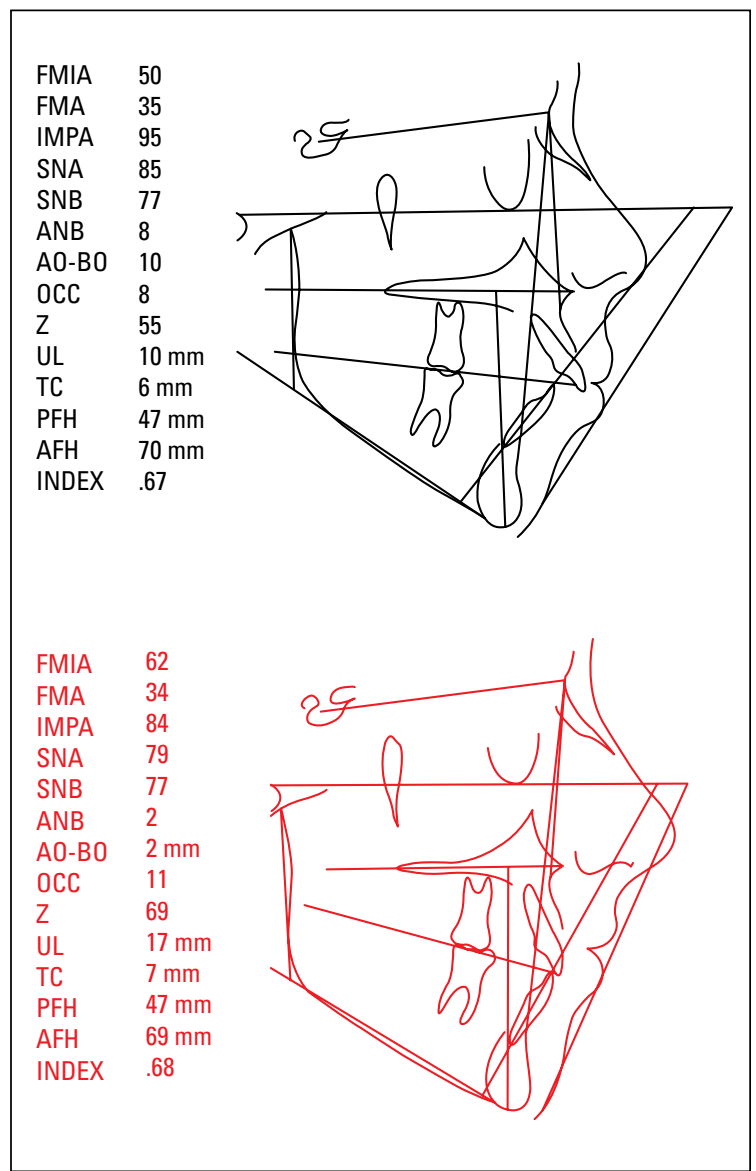

FIGURE 14D - Pretreatment and posttreatment tracings: The profile line to nose relations has been altered.

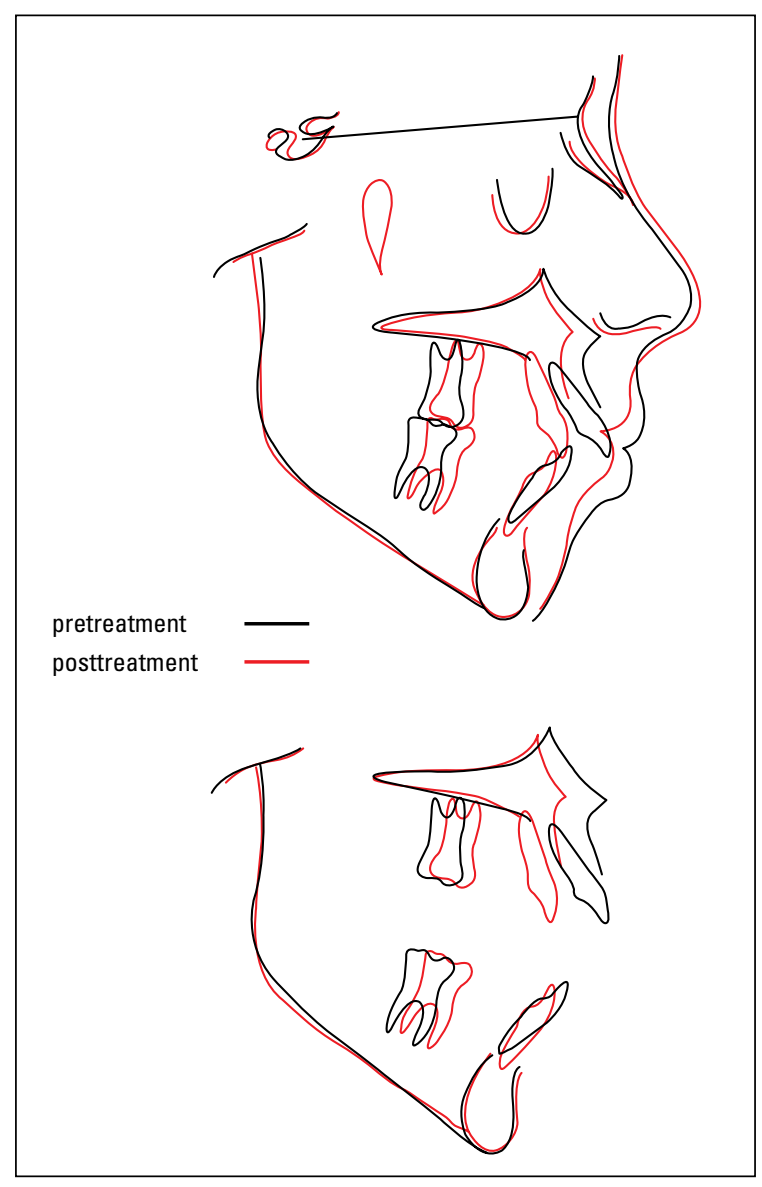

FIGURE 14E - Superimpositions. 
companies have upon the specialty. It's much more profitable for the supply company to sell a preadjusted self ligating bracket than it is to sell a standard nonprescription bracket. Think about the amount of money that's at stake? This is why the supply companies tout the magic appliances. It's a money driven system. I don't know if the way that I treat patients, or that Jack Dale or Herb Klontz treats patients, is more accepted now than it was. I think it has always been accepted and we've always been looked upon to provide some fundamentals to the orthodontic specialty. Without fundamentals, nothing is successful. You can treat a patient with any appliance as long as you adhere to the fundamentals of treatment planning and of force systems. One doesn't have to use a standard edgewise appliance with the Tweed-Merrifield force system to achieve an esthetic, healthy, functional and stable result. If this result is to be achieved, however, one must adhere to fundamentals of treatment planning within the dimensions of the dentition concept and use a carefully controlled force system. Because the specialty gradually drifted away from these things, many now realize how important they are. Hence, the "revival" of requests for information from Jack Dale, Herb Klontz, etc. We have found that the Tweed Study Course is more popular than ever. In fact, in 2009 we had to have three courses because of demand. More than 30 of the 60 American Universities now send all of their students to Tucson to take the Tweed Study Course. The reason this is done is because the people in charge of these programs realize that the fundamentals are important. They understand that in the two week study course the student is absolutely saturated with fundamentals of diagnosis, treatment planning, and archwire manipulation. The successful orthodontist must know these things. We feel that the student who learns them, no matter what appliance he/she uses, will be a better clinician.

One of the most cited critique to the TweedMerrifield mechanics is the using of High-Pull
Headgear with "J" hooks. With the temporary anchorage devices (mini-implants) arrival, is it possible to integrally apply TweedMerrifield mechanics without the headgear? Hiroshi Maruo

The application of forces with miniscrews instead of a headgear might work in certain instances-particularly in adult treatment. Adults are not growing. Miniscrews can be used very successfully in adult treatment to preserve anchorage, to intrude incisors, etc. In the growing patient, however, there is no substitute for the benefit of anchorage preparation and Class II elastics. Those of us who use this system firmly believe that it allows the patient's genetic potential for a spatial change in the relationship of the maxilla to the mandible to favorably express itself. Implants cannot allow this relationship to express itself because there is no constant Class II elastic force. Therefore, the use of Class II elastics, anterior vertical elastics and headgear are fundamental. It would be very difficult to use miniscrews instead of the highpull headgear to apply the proper force system. The headgear can be varied from maxillary arch to mandibular arch, from maxillary canines to hooks placed between the maxillary central and lateral incisors. Forces applied from miniscrews cannot be used with such variation. One would have to use six or eight implant sites to achieve the same thing one can achieve with a J-hook highpull headgear. It just doesn't seem practical. It is putting the patient through a lot of unnecessary trauma and implant placement. The headgear is much safer and much more reliable. Therefore, as I see it, the J-hook headgear is here to stay; miniscrews are also here to stay, but should be used only when indicated. The versatility of the two is not comparable. The J-hook headgear wins the versatility contest.

The Tweed-Merrifield mechanics is quite suitable for the treatment of Class II malocclusions in "long face" patients (high FMA angle). Among the many cases treated by Dr. Vaden, the Class II treatments in "short face" 
patients (low FMA angle) are very impressive. Considering the Tweed-Merrifield mechanics, which are the differences in the Class II treatment between "short face" and "long face" patients? Hiroshi Maruo

"Short face" patients must be treated by leaving mandibular incisors in their pretreatment positions. They cannot be pushed forward to ameliorate crowding or to level the curve of Spee. Long face patients must have overly upright mandibular incisors and the subsequent retraction of maxillary incisors. The vertical control of the maxillary and mandibular molars is much more critical in long face patients than in short face patients. If molars are not controlled in the long face patient, the chin will rotate down and back and the face is irreparably harmed (Fig 15). While molar vertical exclusion in the short face patient is, or might be beneficial, it's extremely hard to accomplish with any degree of stability. It's almost not fair that the patient on whom you want no vertical extrusion will get it quickly and it does irreparable damage, while the short face patient cannot seem to sustain any kind of vertical molar extrusion because of the musculature. Constrictive, intrusive forces must be used on long face patients. It is not so critical to use them on short face patients.

In your opinion, are there any change in the fundamental principles of orthodontics due to the advancement of new technologies? Ana Maria Bolognese

Ana Maria's question is very interesting. My answer is an unequivocal "NO" - FUNDAMENTALS DO NOT CHANGE. Appliances might change, treatment mechanics might change, but fundamentals don't change. The fundamentals of achieving esthetics, health, function, stability and treatment in harmony with growth have been with us since the day of Kingsley and Angle. These things have been debated and people have tried to change them to suit their individual treatment planning, force systems or whims, but these changes haven't lasted. Fundamentals will stay with us. It's important to know, appreciate, and understand the fundamentals in order to use any type of orthodontic appliance and force system. If you deviate from fundamentals, you will compromise the esthetics, health, function, stability and treatment and harmony with growth.

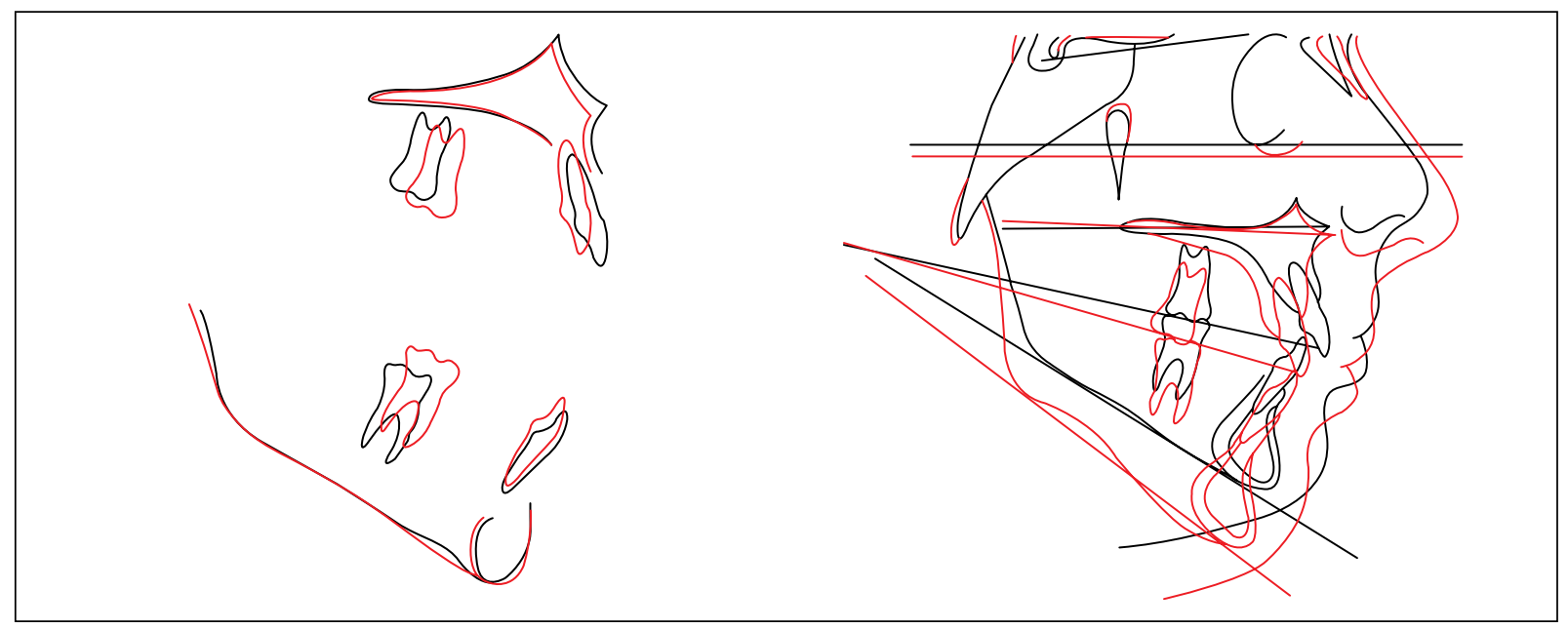

FIGURE 15 - Molar extrusion yields a "down and back" mandibular rotation. 
It is undeniable the efficiency of the TweedMerrifield philosophy in the mechanics of anchorage preparation and control of facial growth. Is there any indication to associate absolute skeletal anchorage in patients where growth has already ceased? Ana Maria Bolognese

There is absolute skeletal anchorage with the use of miniscrews. The Koreans and Japanese have perfected this approach. An excellent case report that I use as a "standard" for this type of treatment was published in the American Journal of Orthodontics DentoFacial Orthopedics by J M Chae 2 . My prediction is that miniscrew anchorage will be the tool that the serious orthodontist uses to help with the correction of the severe adult malocclusion I think most orthodontists will probably not use these devises in most growing patients because there are so many other things that will offer more versatility of application. For the patient who has no growth potential, however, the miniscrew skeletal anchorage system has many advantages because vertical and horizontal control of the dentition is made so much easier.

\section{How do you see the future of Orthodontics? Estelio Zen}

My answer is simple: I'm very worried about the future of Orthodontics. It seems that the influence of the supply houses and the desire of many in the specialty to see how many patients can be run through an office in a day and how much money could be made is going to destroy the quality of orthodontic care. If this trend does not reverse itself, we then become a specialty that is doing nothing but aligning teeth. There is a difference between an orthodontist and a tooth alignment specialist. If we, as a specialty, do nothing but align teeth; if we do not create or maintain good faces; if we do not give our patients a treatment result that is stable in the long term without permanent retention; if our result is not healthy and functional the specialty will become extinct. The general dentist in any country in the world can stick some brackets on the teeth, use some magic wire and align the teeth. We as a specialty must come back to the realization that we have an obligation to each patient to give the patient the very best that orthodontics has to offer. Now I refer to an editorial written by Lysle Johnston, ${ }^{1}$ in the World Journal of Orthodontics, entitled "When Everything Works and Nothing Matters". Unless we begin to realize that things do matter, our long term survival is in jeopardy. On a positive note, there are some glimmers of hope. Many clinicians are becoming disenchanted with the magic appliances. There seems to be a resurgence in the fundamentals of treatment planning and of archwire manipulation. The Tweed Study Course has never been more popular than it is today. I have met many young people who are doing a very good job in their practices. They are interested in quality and not quantity. So, even though the pendulum has swung too far toward appliance driven treatment, it seems to be swinging back toward treatment planning with a concern for facial esthetics and long-term stability. Many of the young people we see are limiting their practice to the number of patients they can comfortably see and are limiting their staff size so that the overhead expenses are compatible with their income. One of the big problems that all students now have to solve is debt. Student debt forces many young orthodontists to do things they know they shouldn't be doing. If we could get a handle on student debt, I think the pendulum would swing back toward the center even faster. So, there is doom and gloom, but there are very, very good indications that the patients of the next generation of orthodontists will be better served than they are now being served.

What message you give to the Brazilian orthodontists for getting the certification of the Brazilian Board of Orthodontics and Facial Orthopedics - BBO? Estelio Zen

Board certification, if done for the right reason, is a tremendous learning experience. The orthodontist who is board certified makes himself/herself look at the work that he/she is 
rendering to the patients who seek care. Self examination is a good thing. Peer examination is a good thing. If your work is evaluated and accepted by your peers, then you are doing standard of care treatment for your patients. It becomes a proven fact that you're a better orthodontist if you examine yourself and if you allow your peers to examine you. It's got to make you better. Board certification is something the specialist must do for himself/herself. It's not something you do for "notoriety." Board certification is going to be one of the things that saves the specialty of orthodontics. I encourage all Brazilian orthodontists to examine themselves and let their peers examine their work. This is a giant step toward standard of care. It will definitely help every orthodontist be better than if he/ she had not entered the certification process. It makes the specialty better and greatly benefits the patients we all serve. There is no down-side to becoming board certified - whether you live in France, Japan, Australia, the United States of America or Brazil!

\section{Adilson Thomazinho \\ - PhD at the College of Dentistry, Ribeirão Preto / USP (FORP-USP). \\ - Coordinator of the Specialization Course in Orthodontics (FORP-USP).}

\section{Ana Maria Bolognese}

- PhD in Orthodontics at Northwestern University. - Doctorate in Dentistry, Federal University of Rio de Janeiro (UFRJ).

- Master in Orthodontics, UFRJ.

- Specialist in Radiology, UFRJ.

- Former Director and Chairman of the Brazilian Board of Orthodontics and Facial Orthopedics.

- Withholder of Prof. Édimo José Soares Martins Commendation.

\section{Estelio Zen}

- Post-graduated in Orthodontics, Federal University of Rio de Janeiro (UFRJ).

- Master in Orthodontics, UFRJ.

- Former director and chairman of the Brazilian Board of Orthodontics and Facial Orthopedics.

- Withholder of Édimo José Soares Martins Commendation.

- Associate and director of BBO.

\section{Hiroshi Maruo \\ - PhD in Orthodontics, State University of Campinas / Piracicaba. \\ - Master in Orthodontics, Unicamp / Piracicaba. \\ - Specialist in Dental Prosthesis, Unicamp / Piracicaba. \\ - Graduated by the Brazilian Board of Orthodontics and Facial Orthopedics.}

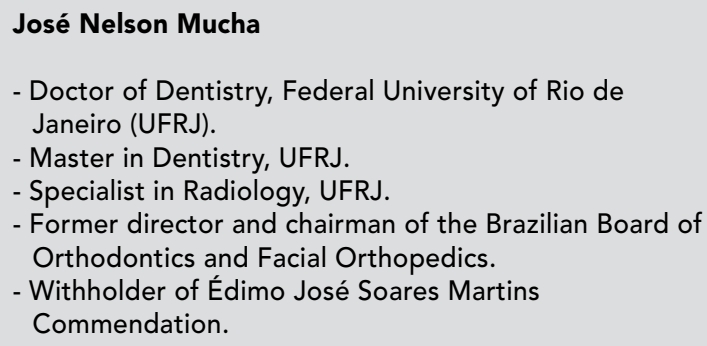

\section{Contact address}

James L. Vaden, D.D.S., M.S., P.C

308 East 1st Street, Coolville, TN 38501. USA 